\title{
¿Cuándo puedo comparar un mismo test realizado en diferentes laboratorios? Conceptos de trazabilidad y armonización en el laboratorio clínico
}

Ana María G uzmán D, Sandra Solari G .

\section{Traceability and harmonization in clinical laboratory}

The results of a determination performed in two different laboratories can only be compared if the techniques used are comparable, independently of the methodology or manufacturer. For this purpose, methods must be traceable to common materials and methods. Despite the common sense of this statement, only few laboratory determinations fulfill this requisite. In general, during the follow up of a patient, the physician must try to use the same laboratory or at least laboratories that use the same method. Moreover, laboratories should define the method used for determinations in their reports as an indispensable information for attending physicians (Rev Méd Chile 2009; 137: 713-5).

(Key w ords: Reference standards; Observer variation)

RESUMEN

Los resultados de un mismo examen realizado en dos laboratorios diferentes, sólo se pueden comparar si las técnicas utilizadas son comparables, independientemente del fabricante o metodología. Para que ello ocurra, los métodos deben ser trazables a un material y a un método de referencia común. A pesar de que esto parece obvio, sólo unos pocos exámenes de laboratorio logran esta condición. En general, y especialmente en el seguimiento o control de los pacientes, el médico debe optar por usar siempre el mismo laboratorio o laboratorios que utilicen el mismo método. Además, los laboratorios clínicos deben explicitar el método utilizado en su informe de Resultados, como información indispensable para la correcta interpretación por parte del médico tratante.

Departamento de Laboratorios Clínicos, Facultad de Medicina. Pontificia Universidad Católica de Chile. Santiago de Chile.

\section{DE LA VIDA REAL}

Un paciente de 65 años concurre a un chequeo anual en el cual se le solicita, además de exámenes generales, un antígeno prostático específico (PSA), el cual arroja un valor de 3,5 ng/mL Al año siguiente, vuelve a control y su PSA, realizado en otro laboratorio, es de 4,2 ng/mL El médico indica biopsia, que resulta normal. El PSA repetido, pero realizado en el primer laboratorio arroja un valor de 3,6 $\mathrm{ng} / \mathrm{mL}$

¿Qué hubiera sucedido si el paciente se hubiera realizado su PSA de control en el mismo laboratorio? 
El objetivo primario de la Medicina de Laboratorio es entregar al médico clínico información que le sea de utilidad en el proceso de decisión médica. En un mundo globalizado, uno de los desafíos más importantes es contar con resultados de laboratorio comparables en cualquier lugar donde se encuentre el paciente ${ }^{1}$.

Para lograr que un método sea comparable a nivel mundial, la estrategia más importante es lograr la trazabilidad del mismo. De acuerdo al vocabulario metrológico, trazabilidad es "la propiedad de un resultado de medición, que permite relacionarlo a una referencia documentada, usualmente nacional o internacional, a través de una cadena ininterrumpida de comparaciones que establecen una incertidumbre conocida"2.

Normalmente la trazabilidad de un valor de un examen de laboratorio, es establecida por una serie de mediciones de materiales de referencia utilizadas en orden jerárquico (Figura 1). Lo ideal sería omitir todos los pasos intermedios y medir la muestra en rutina con un método de referencia, pero esto es imposible en la práctica corriente.

Por esto, un paso clave, especialmente a nivel de los fabricantes de reactivos, ha sido definir que los valores asignados del material control o calibrador deben ser trazables a un material o método de referencia. Además, este material control debe ser conmutable, propiedad que indica que se comporta como una muestra clínica que carece de efecto matriz. Así, diferentes métodos resultan armonizados o estandarizados entre sí (independiente del método, procedimiento de medida y el laboratorio donde el test es realizado) y por lo tanto, comparables ${ }^{3}$. Si existe un material y método de referencia los resultados obtenidos serán además exactos o muy cercanos a la verdad (Figura 2).

$\mathrm{Si}$ los resultados son comparables, lograremos concordancia de nomenclatura, definiciones, metas analíticas, intervalos de referencia, aplicación de procedimientos comunes en el laboratorio y reducción de errores analíticos. Además, los resultados de las publicaciones y sus conclusiones serán también comparables, logrando finalmente puntos de corte y guías clínicas comunes a nivel mundial. Estas guías clínicas, a su vez, estandarizarán los procesos en los Servicios Clínicos, disminuyendo los errores en el cuidado del enfermo y colaborarán directamente en la seguridad del paciente, meta central para los centros de salud y para la Joint Commission on the Accreditation of Healthcare Organizations (JCAHO) ${ }^{4}$.

Tan real es la necesidad de lograr métodos comparables, que en el año 2002 se formó un Comité para la Trazabilidad en Medicina de Laboratorio (Joint Committee for Traceability in Laboratory Medicine) avalado por el Bureau International des Poids et Mesures (BIPM), la International Federation of Clinical Chemistry (IFCC) y la International Laboratory Acreditation Cooperation (ILAC) ${ }^{2}$.

A pesar de estos esfuerzos recientes, hasta ahora las guías clínicas se han desarrollado indicando acciones o tratamientos a determinado nivel de un analito, independiente del método utilizado para la medición. Este es el caso del PSA colocado en el ejemplo de la "vida real", en el cual actualmente existen dos calibradores disponibles comercialmente, los cuales no sólo obtienen valores distintos, sino que inducen a decisiones diferentes con los pacientes: se sabe que 19\% de

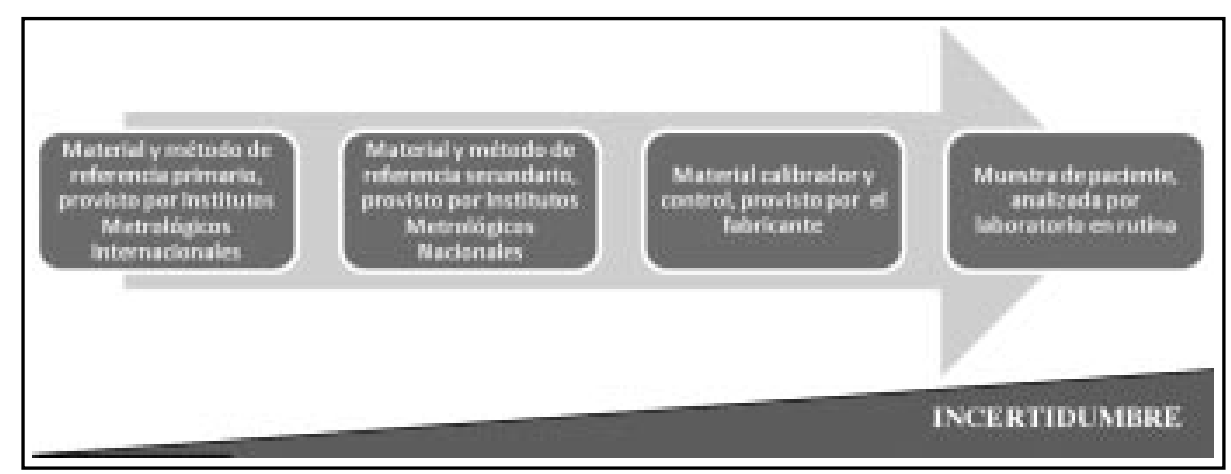

Figura 1. Concepto de trazabilidad. 


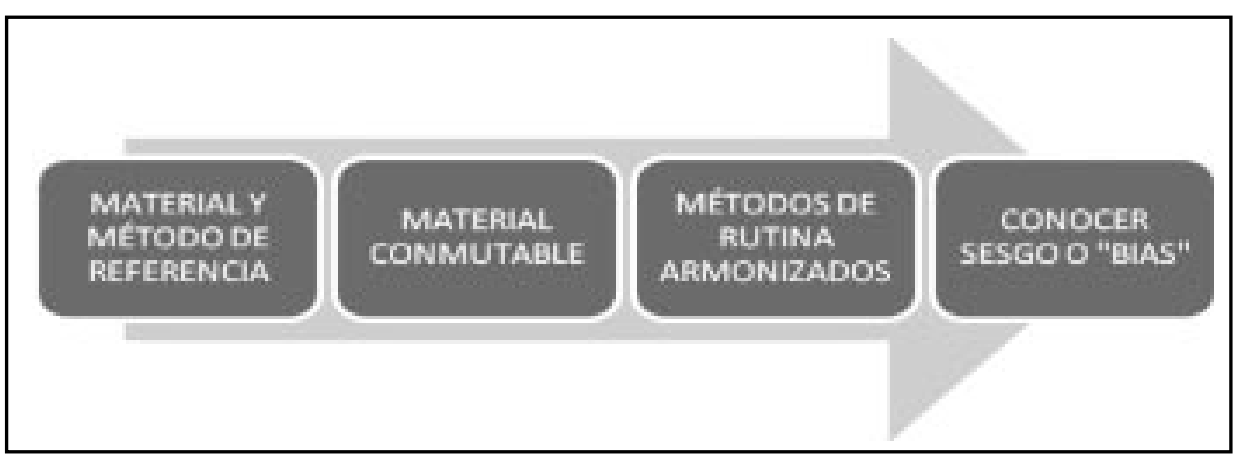

Figura 2. Armonización de métodos de laboratorio.

los pacientes son candidatos a biopsia si la muestra para PSA es analizada con un calibrador, pero no con el otro $\mathrm{y}$, sin embargo, ambos métodos utilizan el mismo y tradicional punto de corte de $4 \mathrm{ng} / \mathrm{mL}^{5}$.

Un ejemplo mejor llevado es el colesterol, en el cual se han hecho esfuerzos por parte del Center for Disease Control and Prevention (CDC) y su Programa de Estandarización de Lípidos, el cual utiliza un suero conmutable (que se comporta como muestra clínica, sin interferentes y preparado según las normas) y que es enviado 4 veces al año a más de 150 laboratorios en el mundo. Este suero tiene un valor asignado por un método de referencia, lo que permite a los laboratorios participantes conocer la exactitud de sus valores individualmente. Así, para establecer los niveles

\section{REFERENCIAS}

1. Panteghini M. Traceability, reference systems and result comparability. Clin Biochem Rev 2007; 28: 97 104.

2. Armbruster D, Miler R. The Joint Committee for Traceability in Laboratory Medicine: A global approach to promote the standardization of clinical Laboratory test results. Clin Biochem Rev 2007; 28: 105-13.

3. MiLeR W. Specimens materials, target values and commutability for external quality assessment schemes. Clin Chim Acta 2003; 327: 25-37.

4. Joint Commission on the Accreditation of Healthcare Organizations. National Patient Safety Goals. Disponible en: htpp:/www.jcaho.org/accreditedorganizations/patientsafety/npsg.htm [Consultado el 17 de marzo de 2009]. de riesgo de enfermedad ateroesclerótica, los valores de colesterol $\mathrm{LDL}>160 \mathrm{mg} / \mathrm{dL}$ o $\mathrm{HDL}<40$ $\mathrm{mg} / \mathrm{dL}$, son aplicables mundialmente ${ }^{6}$.

En otros ensayos es tal la falta de estandarización que los resultados no son equivalentes, con valores de referencia distintos según el método, unidades de varias órdenes de magnitud distintas y valores de corte totalmente diferentes (troponina, proteína $\mathrm{C}$ reactiva, etc.) que al médico le resulta obvio que no puede comparar los resultados ${ }^{7}$.

En resumen, la disponibilidad de resultados de laboratorio comparables, es todavía un desafío en la Medicina de Laboratorio. En forma práctica, el médico debe optar por controlar a un paciente en un mismo laboratorio y, si no es posible, al menos realizarlo en un laboratorio que trabaje con la misma metodología.

5. Link RE, Shariat SF, Nguyen CV, Farr A, Weinberg AD, Morton RA ET AL. Variation in Prostate specific antigen results from 2 different assay platforms: clinical impact in 2304 patients undergoing prostate cancer screening. J Urol 2004; 171: 2234-8.

6. Cobbaert C, Weykamp C, BaAdenhuijsen H, Kuypers A. Selection, preparation and characterization of commutable frozen human serum pools as potential secondary reference materials for lipid and apolipoprotein measurements: study within the framework of the Dutch project "Calibration 2000". Clin Chem 2002; 48: 1526-38.

7. Christenson RH, Duh SH, Apple FS, Bodor GS, Bunk DM, Panteghini M ET AL. Toward Standardization of Cardiac Troponin I Measurements: assessing commutability of candidate reference materials and harmonization of cardiac troponin assays. Clin Chem 2006; 52: 1685-92. 